\title{
Rutenyum Katkılı Nanotüp Kullanılarak Süperkapasitör Elektrot Üretimi
}

\author{
Murat Akdemir ${ }^{1 *}$ \\ 1* Siirt Üniversitesi, Mühendislik Fakültesi, Elektrik Elektronik Mühendisliği Bölümü, Siirt, Türkiye (ORCID: 0000-0001-9235-1913), muratakdemir@ siirt.edu.tr
} (İlk Geliş Tarihi 14 Ekim 2021 ve Kabul Tarihi 6 Aralık 2021)

(DOI: $10.31590 /$ ejosat.1009731)

\begin{abstract}
ATIF/REFERENCE: Akdemir, M. (2021). Rutenyum Katkı1ı Nanotüp Kullanılarak Süperkapasitör Elektrot Üretimi. Avrupa Bilim ve Teknoloji Dergisi, (31), 326-330.

$\ddot{O} \mathbf{z}$

Çeşitli enerji depolama malzemeleri arasında süperkapasitörler, enerjiyi daha hızlı depoladıkları ve aktardıkları için son zamanlarda daha çok tercih edilmektedirler. Bu çalışma kapsamında, Rutenyum katkılama yapılmış karbon nanotüp kullanılarak süperkapasitör elektrot aktif malzemesi hazırlanmıştır. Daha sonra bu malzeme püskürtme yöntemi kullanılarak elektrotlara dönüştürülmüş ve bir süperkapasitör hücresi hazırlanmıştır. Elektrolit çözeltisi olarak $6 \mathrm{M} \mathrm{KOH}$ seçilmiş ve süperkapassitörün elektriksel özellikleri elektrokimyasal analiz yöntemleri kullanılarak test edilmiştir. Süperkapasitörün eşdeğer seri direnci çok düşük olduğundan kapasitörün güç aktarımının yüksek seviyelerde yapılabilmesini destekler ve malzemenin iç direncinden kaynaklı enerji kayıpları ihmal edilecebilecek seviyelerdedir. $1 \mathrm{~A} / \mathrm{g}$ akım yoğunluğunda elektrotların spesifik kapasitans değeri 42,24 F/g olarak hesaplanmıştır. Elektrotların kapasitesinde 100 döngü sonucunda sadece \%4,1'lik bir azalma olmuştur. Elde edilen veriler 1şığında hazırlanan elektrotların yüksek kapasitesi, düşük iç direnci ve yüksek kararlılığı nedeniyle enerji depolama alanında umut vaat ettiği düşünülmektedir.
\end{abstract}

Anahtar Kelimeler: Nanotüp, Rutenyum, Süperkapasitör, Enerji Depolama.

\section{Supercapacitor Electrode Production Using Ruthenium Doped Nanotube}

\begin{abstract}
Among the various energy storage materials, supercapacitors are more preferred recently as they store and transfer energy faster. In this study, supercapacitor electrode active material was prepared using Ruthenium-doped carbon nanotubes. Then, this material was converted into electrodes using sputtering method and a supercapacitor cell was prepared. $6 \mathrm{M} \mathrm{KOH}$ was chosen as the electrolyte solution and the electrical properties of the supercapacitor were tested using electrochemical analysis methods. Since the equivalent series resistance of the supercapacitor is very low, it supports the power transfer of the capacitor at high levels, and the energy losses due to the internal resistance of the material are at negligible levels. The specific capacitance value of the electrodes was calculated as $42.24 \mathrm{~F} / \mathrm{g}$ at a current density of $1 \mathrm{~A} / \mathrm{g}$. There was only a $4.1 \%$ reduction in the capacity of the electrodes after 100 cycles. It is thought that the electrodes prepared in the light of the obtained data are promising in the field of energy storage due to their high capacity, low internal resistance and high stability.
\end{abstract}

Keywords: Nanotube, Ruthenium, Supercapacitor, Energy Storage.

\footnotetext{
*Sorumlu Yazar: muratakdemir@siirt.edu.tr
} 


\section{Giriş}

Enerji toplumların gelişiminde hayati bir öneme sahiptir. Fosil yakıtların yanması sonucu elde edilen enerji dünya ekonomisini ve çevreyi ciddi şekilde etkilemektedir. Bu da bilim adamlarını çevre dostu alternatif enerji kaynaklarına yönlendirmektedir. Alternatif enerji kaynakları ile üretim gün içinde ve hatta aylara göre değişiklik gösterebildiği için enerji depolama büyük önem kazanmakta ve çevre dostu, yüksek performanslı yenilenebilir enerji depolama cihazlarına olan talep sürekli artmaktadır. Elektrokimyasal enerji, temiz enerjinin kaçınılmaz bir parçasıdır. Piller, süperkapasitörler ve yakıt hücreleri, elektrokimyasal enerji dönüşümü prensibi ile çalışan geleneksel olmayan enerji cihazlarıdır (Sharma et al., 2019; Zhang ve Zhao, 2009). Elektrokimyasal enerji dönüşümü prensibi ile çalışan enerji depolama malzemeleri arasında süperkapasitörler, enerjiyi daha hızlı depoladıkları ve aktardıkları için daha çok tercih edilmiştir. Enerjiyi statik olarak depolayan süper kapasitörler, kapasitörlerden çok daha fazla enerji depolayabilirken, bu enerjiyi elektrokimyasal pillerden yaklaşık on kat daha hızlı aktarabilirler (Pandolfo ve Hollenkamp, 2006).

Süperkapasitörler, elektrik enerjisini ya elektrot yüzeyindeki elektrolit iyonlarının oluşturduğu elektrokimyasal çift katmanda (EDL) ya da elektrot malzemelerinin yüzey bölgelerini içeren redoks reaksiyonları ile faradaik olarak depolar (Conway, 2013; Simon ve Gogotsi, 2010). EDLC mekanizmasında, elektrot ve elektrolitin sınır yüzeyinde çift bir yük tabakası oluşurken, redoks mekanizmada aktif malzeme bir faradaik redoks reaksiyonuna girer. Süper kapasitörler, yüksek güç yoğunluğu, mükemmel hız kapasitesi, uzun süreli ve kararlı çevrim ömrü gibi faydalı özelliklerinden dolayı elektronik iletişim, havacılık, elektrikli ulaşım vb. göze çarpan enerji depolama platformlarında kullanılmaktadırlar (Mohanty et al., 2021). EDL kapasitörler (EDLC'ler) üstün güç yoğunluğunu yüksek elektriksel iletkenlik ve yüksek yüzey alanının birleşiminden aldığından, sağlam ve verimli cihazlar için bu özelliklerin her ikisine de sahip malzemeler gereklidir (Sheberla et al., 2017). Bu tür malzemeler nadirdir. Şimdiye kadar EDLC'lerde kullanılan aktif malzemeler, aktifleştirilmiş, şablonlanmış ve karbürden türetilmiş karbonlar, karbon nanotüpler ve yakın zamanda grafen türü karbonlardır (Gu ve Yushin, 2014; Xu et al., 2014; Y. Zhu et al., 2011). Karbon bazlı malzemeler bol, düşük maliyetli, üretimi kolay, toksik olmayan, daha yüksek spesifik yüzey alanine sahip, iyi mekanik özellik, iyi elektronik iletkenlik, yüksek kimyasal kararlılık ve geniş çalışma sıcaklığı aralığı gibi birçok avantajlara sahiptirler (Pandolfo ve Hollenkamp, 2006; H. Wang ve Cui, 2019; Y. Wang et al., 2021). Son zamanlarda süperkapasitörler üzerine yoğun çalışmalar yapılmaktadır. Kerli (2017) tarafından yapılan çalışmada, indirgenmiş grafen oksit/çinko oksit kompozit malzemesi elektrot materyali olarak hidrotermal yöntem kullanılarak üretilmiştir. Yapılan hesaplamalar sonucunda elektrotların spesifik kapasitans değeri 24,15 F/g olarak bulunmuştur (KERLİ, 2017). Yumak (2019) tarafından yapılan başka bir çalışmada fistık kabuklarından piroliz ve kimyasal aktivasyon teknikleri kullanılarak aktif karbon üretilmiş ve bu aktif karbonun yüzeyinde $\mathrm{MnO} 2$ sentezlenmiştir. Elektrotların spesifik kapasitans değeri $68 \mathrm{~F} / \mathrm{g}$ olarak hesaplanmıştır (Yumak, 2019).

Karbon nanotüpler (CNT'ler), iyi mekanik mukavemetleri, yüksek spesifik yüzey alanları ve önemli elektrik iletkenlikleri nedeniyle elektrikli çift katmanlı kapasitör elektrotlarının tasarımında tipik ve yaygın olarak kullanılan karbon malzemelerdir (Ma et al., 2021; Niu et al., 2020). Daha da önemlisi, CNT'ler elektron ve iyon taşıma yollarını kısaltmak için birbirine bağlı iletken gözenekli ağ yapıları oluşturabilir (Cao et al., 2018; Li et al., 2016). Hidrojen enerjisi üretiminde Rutenyum metali aktif karbonlara katkılama yapılarak malzemenin etkinliğini artırmak için kullanılmaktadır (Avci Hansu et al., 2021). Bu çalışma kapsamında, diğer çalışmalardan farklı olarak ilk kez Rutenyum katkılı nanotüp kullanılarak iki elektrotlu bir süper kapasitör hücresi hazırlanmıştır. Süperkapasitörün kapasitansı, empedansı ve kararlılığı elektrokimyasal yöntemler kullanılarak incelenmiştir.

\section{Materyal ve Metot}

Çalışma kapsamında kullanılacak 0,05 g karbon nanotüp üzerine $10 \mathrm{ml}$ saf su ilave edildi. Miknatıs yardımıyla mikserde karışmaya bırakıldı. Daha sonra bu karışıma karbon nanotüpün ağırlıkça \%3 oranında Rutenyum metali ilave edildi. Elde edilen karışım 40 dakika ultrasonik banyoda ve 80 dakika mikserde bekletildi. Karıştırıldıktan sonra, metal içeren çözeltiye sodyum borhidrür $\left(\mathrm{NaBH}_{4}\right)$ çözeltisi ilave edildi. Yine su banyosunda 20 dakika mikserde 40 dakika bekletildi. Son olarak sentezlenen malzeme filtre kağıdı yardımıyla süzüldü ve filtre kağıdı üzerindeki çökelti vakumlu bir firında $85{ }^{\circ} \mathrm{C}$ 'de 12 saat kurumaya bırakıldı. Püskürtme makinasında rahat sıkılabilmesi kurutulan malzeme bir havan kullanılarak ince bir şekilde ögütüldü. Malzemenin akım toplayıcı üzerine iyi tutunması için malzemeye CNT'nin ağırlıça \%10 oranında bağlayıcı olarak poliviniliden florür (PVDF) eklendi. Elde edilen karışım 10 dakika ultrasonik banyoda tutulduktan sonra manyetik karıştırıcıda 80 dakika karıştırıldı. Bulamaç daha sonra akım toplayıcı olarak kullanılacak nikel köpüğün üzerine püskürtüldü. PVDF çözücüsü olarak kullanılan N-Metil-2-Pirrolidon'i uzaklaştırmak için nikel köpük etüvde $80{ }^{\circ} C^{\prime}$ de 24 saat bekletilmiştir. Anot ve katot hücreleri, firından çıkarılan nikel köpügün 15 mm'lik eşit dairesel çaplarda kesilmesiyle hazırlanmıştır. $18 \mathrm{~mm}$ 'lik kağıt ayırıcı, anot, katot ve $6 \mathrm{M} \mathrm{KOH}$ elektrolit çözeltisi, iki elektrotlu hücre konfigürasyonunu oluşturmak için sızdırmaz bir alüminyum test aparatına yerleştirildi. Hücrenin elektrokimyasal karakterizasyonu, galvanostatik yüklü deşarj (GCD), döngüsel voltametri (CV) ve elektrokimyasal empedans spektroskopisi (EIS) teknikleri kullanılarak oda sıcaklığında gerçekleştirildi.

\section{Araştırma Sonuçları ve Tartışma}

Rutenyum katkılı CNT kullanılarak 2 elektrotlu bir süperkapasitör hücresi hazırlanmıştır. Süperkapasitörün enerji depolama kapasitesi, kararlılığı ve enerji-güç yoğunluğu elektrtokimyasal karakterizasyon sonucu elde edilen CV eğrileri, empedans eğrileri ve şarj-deşarj eğrileri kullanılarak belirlenmiştir. Şekil 1'de kapasitöre ait 5, 10, 20, 40, 60, 80, 100, 200, 300 ve $400 \mathrm{mV} / \mathrm{s}$ tarama hızlarındaki CV eğrileri verilmiştir. Kapasitrün CV eğrileri ideal eğrilere benzemektedir. Tarama hızı arttıkça eğriler dikdörtgen yapıya yani ideal süperkapasitör CV eğrilerine daha çok benzemektedir. Rutenyum katkılamadan dolayı CV eğrilerinde küçük şiddetli tepeler görülmektedir. Tarama hızları düştükçe $\mathrm{CV}$ eğrileri uç noktalarında sapmalar oluşmaktadır. 

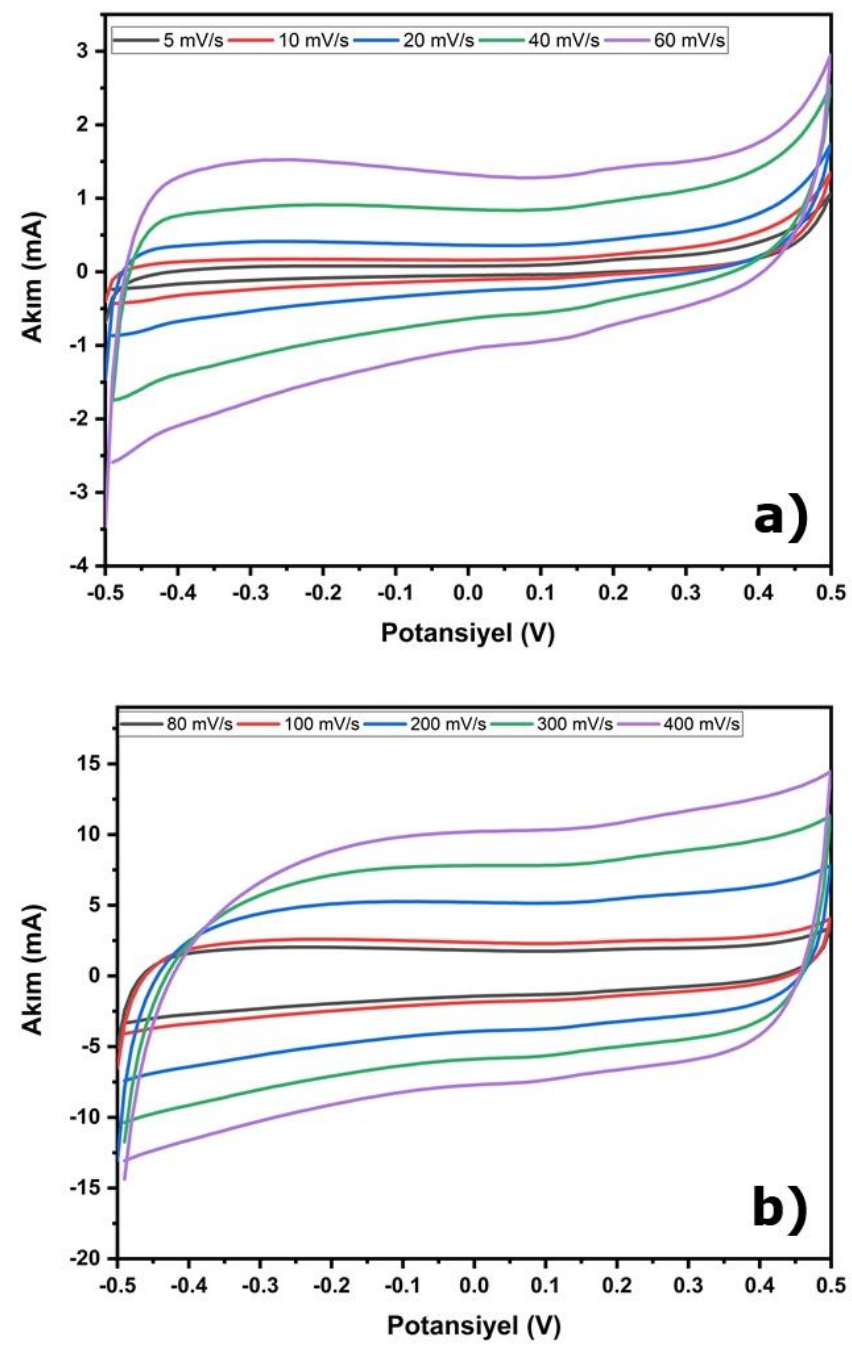

Şekil 1. Süperkapasitör hücresine ait farklı tarama hızlarındaki $\mathrm{CV}$ eğrileri

Elektrotların EIS analizi, $1 \mathrm{~Hz}$ ile $100 \mathrm{kHz}$ frekans aralığında $10 \mathrm{mV}$ genlik ile gerçekleştirilmiş ve sonuçlar Şekil 2 'de verilmiştir. Süperkapasitörün eşdeğer seri direnci $R_{S}$ yaklaşık $0,2 \Omega$ olarak ölçülmüştür. $R_{S}$ direnci çok düşüktür ve bu düşük direnç değeri süperkapasitörün güç aktarımının yüksek seviyelerde yapılabilmesini destekler (Cheng et al., 2011; Yan et al., 2014). Orta frekans aralığındaki yarım daire çap1, arayüzey yük transfer direncini $\left(R_{c t}\right)$ değerlendirmek için kullanılır. Üretilen super kapasitörün $R_{c t}$ direnci $3 \Omega$ olarak hesaplanmıştır. Düşük frekanslarda, empedans eğrilerinin eğimi, elektrolit ile elektrot malzemesi arasındaki difüzyon direncinin olduğunu gösterir. Elektrotlar için eğim $76^{\circ}$ olarak hesaplanmıştır ve bu değer elektrot malzemesinin elektrolit ile iyi bir etkileşime geçtiğini ve difüzyon direncinin düşük olduğunu göstermektedir (Gamby et al., 2001; X. Zhu et al., 2018).

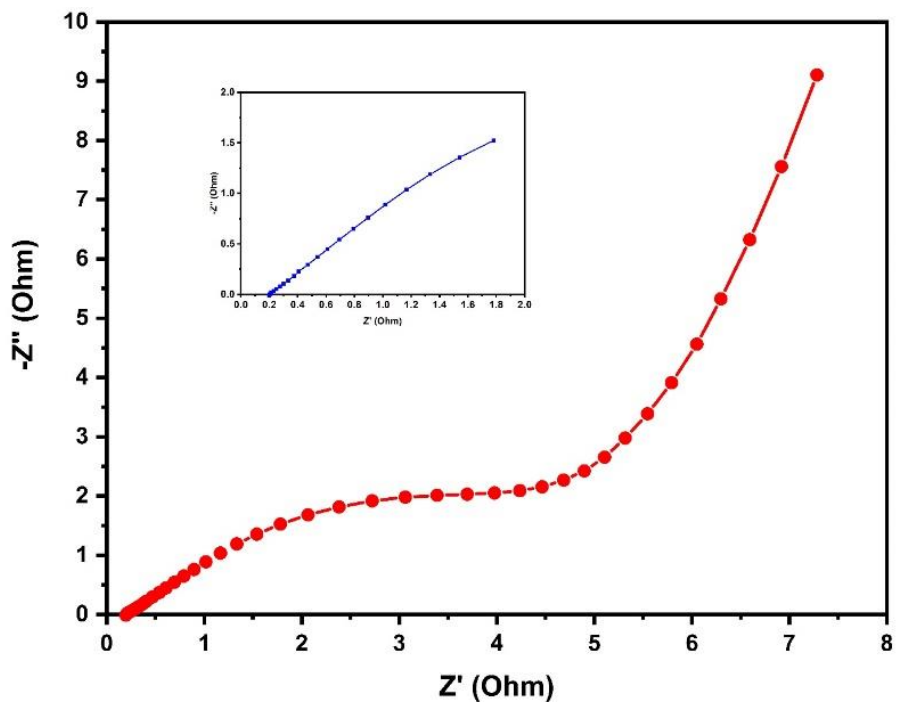

Şekil 2. Hazırlanan süperkapasitöre ait empedans eğrisi

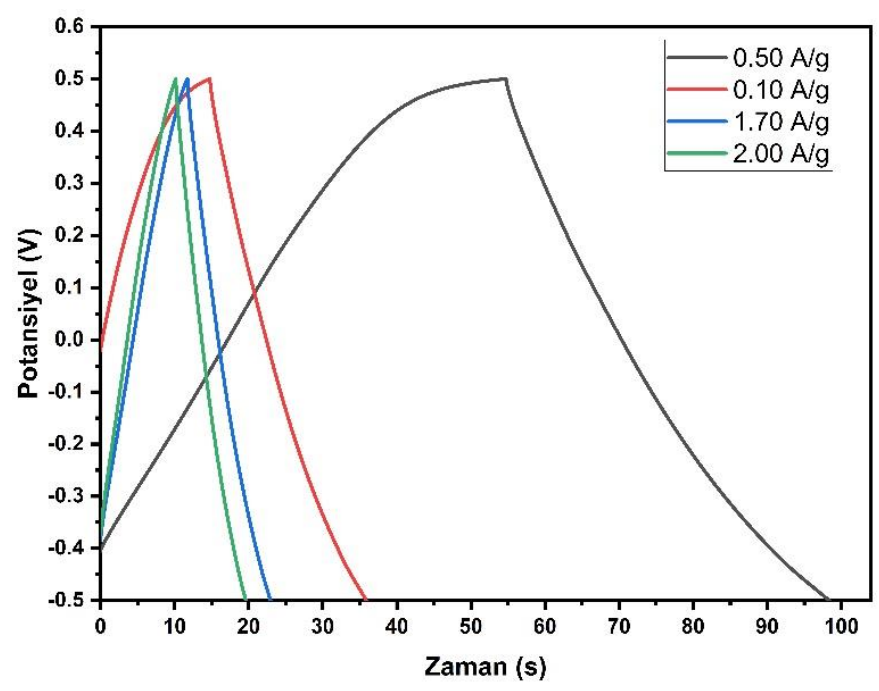

Şekil 3. Süperkapasitör hücresine ait farklı akım yoğunluklarındaki şar-deşarj eğrileri

Hazırlanan elektrotların şarj-deşarj eğrileri galvanostatik şarj deşarj tekniği kullanılarak elde edilmiştir. Hücreye ait farklı akım yoğunluklarındaki şarj-deşarj eğrileri Şekil 3'de verilmiştir. Şarj-deşarj eğrileri ideal süperkapasitör eğrileriyle mükemmel bir benzerlik göstermektedir. Eğrilerin mükemmelliği, elektrot yüzeyleri ile elektrolit sıvısı arasındaki iyon değişiminin hızlı ve tersinir bir şekilde gerçekleştiğini göstermektedir. Deşarj işleminin başlangıcında $0,50 \mathrm{~A} / \mathrm{g}$ 'da yaklaşı $4 \mathrm{mV} ; 1,00 \mathrm{~A} / \mathrm{g}$ 'da $6 \mathrm{mV} ; 1,70 \mathrm{~A} / \mathrm{g}^{\prime} \mathrm{da} 10 \mathrm{mV}$ ve 2,00 A/g'da yaklaşık $12 \mathrm{mV}$ IR düşüşü gözlemlenmiştir. IR düşümleri ihmal edilecek seviyelerde düşüktür ve bu değerler hazırlanan elektrot malzemelerinin iç direncinin düşük olduğunu kanıtlamaktadır (Song et al., 2019). Elektrotların spesifik kapasitansı şarj-deşarj eğrileri kullanılarak Denklem 1 aracılığıyla hesaplanmıştır:

$C=\frac{2 \cdot I \cdot \Delta t}{m \cdot \Delta V}$

Denklemde verilen $\mathrm{m}(\mathrm{g})$, bir elektrot üzerindeki aktif madde miktarını; $\Delta \mathrm{t}(\mathrm{s})$, deşarj süresini; $\mathrm{I}(\mathrm{A})$, akımı; $\Delta \mathrm{V}(\mathrm{V})$, uygulanan gerilim aralığını belirtmektedir. Kapasitans değerleri $0,50 \mathrm{~A} / \mathrm{g}$ için 43,64 F/g; 1,00 A/g için 42,24 F/g; 1,70 A/g için 38,11 F/g, ve $2,00 \mathrm{~A} / \mathrm{g}$ için $37,72 \mathrm{~F} / \mathrm{g}$ olarak hesaplanmıştır. Elektrotların 
kararlılığını belirlemek için $1 \mathrm{~A} / \mathrm{g}$ akım yoğunluğunda 100 döngülük şarj-deşarj analizi yapılmıştır ve sonuçlar Şekil 4'te verilmiştir. 100 döngü sonucunda elektrotlar ilk kapasitelerinin $\% 95,9$ 'ünü halen sürdürmektedirler. $\mathrm{Bu}$ da üretilen elektrot malzemelerinin kararlı bir yapıya sahip olduğunu göstermektedir.

Elektrotların kapasitans değerleri esas olarak kullanılan biyokütle malzemesinin tipine, aktivasyon maddesine, biyokütlenin yakıldığı sıcaklığa, katkı maddesine, hazırlama yöntemine ve kullanılan elektrolit tipine bağlıdır. Hazırlanan elektrotların kapasitans değeri, litaratüde pamuk sap1 (Chen et al., 2013), çay atığı (Özarslan et al., 2021), bambu (Farma et al., 2021) pirinç kabuğu (W. Zhang et al., 2017), Spirulina platensis (Elma Karakaş et al., 2021), Microcystis aeruginosa (Inal et al., 2021), limon kabuğu (Mehare et al., 2021), kahve telvesi atığ 1 (Akdemir et al., 2021), greyfurt kabuğu (Fu et al., 2018), nilüfer kökü (Y. Zhang et al., 2017) ve ceviz kabuğu (Lan et al., 2020) kullanılarak elde edilen aktif karbonlar kullanılarak hazırlanan elektrotların kapasitans değerlerine yakın değerler elde edilmiştir. Elde edilen sonuçlar 1şığında Rutenyum katkılı CNT kullanılarak hazırlanan elektrotların iyi bir enerji depolama kapasitesine ve kararlı bir yapıya sahip olduğu görülmüştür.

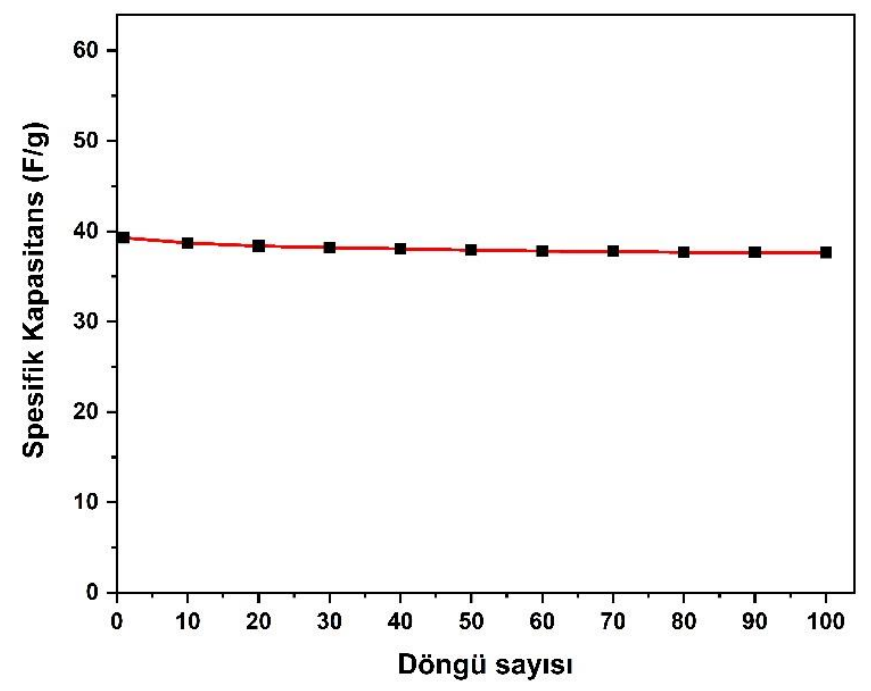

Şekil 4. Süperkapasitör hücresine ait 100 döngülük şarj-deşarj sonrası kapasitans azalması

\section{Sonuç}

$\mathrm{Bu}$ çalışma kapsamında, Rutenyum katkılama yapılmış karbon nanotüp kullanılarak süperkapasitör elektrot aktif malzemesi hazırlanmıştır. Daha sonra bu malzeme püskürtme yöntemi kullanılarak elektrotlara dönüştürülmüş ve bir süperkapasitör hücresi hazırlanmıştır. Elektrolit çözeltisi olarak 6 M KOH seçilmiş ve süperkapassitörün elektriksel özellikleri elektrokimyasal analiz yöntemleri kullanılarak test edilmiştir. Süperkapasitörün eşdeğer seri direnci çok düşük olduğundan kapasitörün güç aktarımının yüksek seviyelerde yapılabilmesini destekler ve malzemenin iç direncinden kaynaklı enerji kayıpları ihmal edilecebilecek seviyelerdedir. $1 \mathrm{~A} / \mathrm{g}$ akım yoğunluğunda elektrotların spesifik kapasitans değeri 42,24 F/g olarak hesaplanmıştır. Elektrotların kapasitesinde 100 döngü sonucunda sadece \%4,1'lik bir azalma olmuştur. Elde edilen veriler ışı̆̆ında hazırlanan elektrotların yüksek kapasitesi, düşük iç direnci ve yüksek kararlılığı nedeniyle enerji depolama alanında umut vaat ettiği düşünülmektedir. Ayrıca farklı aktivasyon yöntemleri ve farklı yakma sıcaklıkları kullanılarak daha büyük kapasiteli elektrotların geliştirilebileceği düşünülmektedir.

\section{Teșekkür}

Siirt Üniversitesi Biyoteknoloji Laboratuvarına değerli katkılarından dolayı teşekkür ederiz.

\section{Kaynakça}

Akdemir, M., Avci Hansu, T., Caglar, A., Kaya, M., \& Demir Kivrak, H. (2021). Ruthenium modified defatted spent coffee catalysts for supercapacitor and methanolysis application. Energy Storage, 3(4), e243. doi:https://doi.org/10.1002/est2.243

Avci Hansu, T., Caglar, A., Demir Kivrak, H., \& Sahin, O. (2021). Structure of ruthenium nanocatalysts of bismuth, investigation of its effect on hydrolysis performance and kinetic studies. Energy Storage, e267.

Cao, X., He, J., Li, H., Kang, L., He, X., Sun, J., . . . Liu, Z. H. (2018). CoNi2S4 nanoparticle/carbon nanotube sponge cathode with ultrahigh capacitance for highly compressible asymmetric supercapacitor. Small, 14(27), 1800998.

Chen, M., Kang, X., Wumaier, T., Dou, J., Gao, B., Han, Y., . . . Zhang, L. (2013). Preparation of activated carbon from cotton stalk and its application in supercapacitor. Journal of solid state electrochemistry, 17(4), 1005-1012.

Cheng, Q., Tang, J., Ma, J., Zhang, H., Shinya, N., \& Qin, L.-C. (2011). Graphene and nanostructured $\mathrm{MnO} 2$ composite electrodes for supercapacitors. Carbon, 49(9), 2917-2925.

Conway, B. E. (2013). Electrochemical supercapacitors: scientific fundamentals and technological applications: Springer Science \& Business Media.

Elma Karakaş, D., Akdemir, M., Atabani, A. E., \& Kaya, M. (2021). A dual functional material: Spirulina Platensis waste-supported $\mathrm{Pd}-\mathrm{Co}$ catalyst as a novel promising supercapacitor electrode. Fuel, 304, 121334. doi:https://doi.org/10.1016/j.fuel.2021.121334

Farma, R., Putri, A., Taer, E., Awitdrus, A., \& Apriwandi, A. (2021). Synthesis of highly porous activated carbon nanofibers derived from bamboo waste materials for application in supercapacitor. Journal of Materials Science: Materials in Electronics, 32(6), 7681-7691.

Fu, G., Li, Q., Ye, J., Han, J., Wang, J., Zhai, L., \& Zhu, Y. (2018). Hierarchical porous carbon with high nitrogen content derived from plant waste (pomelo peel) for supercapacitor. Journal of Materials Science: Materials in Electronics, 29(9), 7707-7717.

Gamby, J., Taberna, P., Simon, P., Fauvarque, J., \& Chesneau, M. (2001). Studies and characterisations of various activated carbons used for carbon/carbon supercapacitors. Journal of Power Sources, 101(1), 109-116.

Gu, W., \& Yushin, G. (2014). Review of nanostructured carbon materials for electrochemical capacitor applications: advantages and limitations of activated carbon, carbide-derived carbon, zeolite-templated carbon, carbon aerogels, carbon nanotubes, onion-like carbon, and graphene. Wiley Interdisciplinary Reviews: Energy and Environment, 3(5), 424-473.

Inal, I. I. G., Akdemir, M., \& Kaya, M. (2021). Microcystis aeruginosa supported-Mn catalyst as a new promising supercapacitor electrode: A dual functional material. 
International Journal of Hydrogen Energy, 46, 2153421541.

KERLİ, S. (2017). İNDİRGENMIŞ GRAFEN OKSİT-ÇINNKO OKSITT-TITANYUM DİOKSITT KOMPOZITT MALZEME ÜRETIMI VE UYGULAMASI. Niğde Ömer Halisdemir Üniversitesi Mühendislik Bilimleri Dergisi, 6(1), 220-225.

Lan, D., Chen, M., Liu, Y., Liang, Q., Tu, W., Chen, Y., ... Qiu, F. (2020). Preparation and characterization of high valueadded activated carbon derived from biowaste walnut shell by $\mathrm{KOH}$ activation for supercapacitor electrode. Journal of Materials Science: Materials in Electronics, 31(21), 1854118553.

Li, D., Gong, Y., \& Pan, C. (2016). Facile synthesis of hybrid CNTs/NiCo 2 S 4 composite for high performance supercapacitors. Scientific reports, 6(1), 1-7.

Ma, Z., Zheng, R., Liu, Y., Ying, Y., \& Shi, W. (2021). Carbon nanotubes interpenetrating MOFs-derived Co-Ni-S composite spheres with interconnected architecture for high performance hybrid supercapacitor. Journal of Colloid and Interface Science, 602, 627-635. doi:https://doi.org/10.1016/j.jcis.2021.06.027

Mehare, M., Deshmukh, A., \& Dhoble, S. (2021). Bio-waste lemon peel derived carbon based electrode in perspect of supercapacitor. Journal of Materials Science: Materials in Electronics, 32(10), 14057-14071.

Mohanty, A., Jaihindh, D., Fu, Y.-P., Senanayak, S. P., Mende, L. S., \& Ramadoss, A. (2021). An extensive review on three dimension architectural Metal-Organic Frameworks towards supercapacitor application. Journal of Power Sources, 488, 229444.

Niu, H., Liu, Y., Mao, B., Xin, N., Jia, H., \& Shi, W. (2020). Insitu embedding MOFs-derived copper sulfide polyhedrons in carbon nanotube networks for hybrid supercapacitor with superior energy density. Electrochimica Acta, 329, 135130. doi:https://doi.org/10.1016/j.electacta.2019.135130

Özarslan, S., Raşit Atelge, M., Kaya, M., \& Ünalan, S. (2021). A Novel Tea factory waste metal-free catalyst as promising supercapacitor electrode for hydrogen production and energy storage: A dual functional material. Fuel, 305, 121578. doi:https://doi.org/10.1016/j.fuel.2021.121578

Pandolfo, A. G., \& Hollenkamp, A. F. (2006). Carbon properties and their role in supercapacitors. Journal of Power Sources, 157(1),

11-27. doi:https://doi.org/10.1016/j.jpowsour.2006.02.065

Sharma, K., Arora, A., \& Tripathi, S. K. (2019). Review of supercapacitors: Materials and devices. Journal of Energy Storage, 21, 801-825.

Sheberla, D., Bachman, J. C., Elias, J. S., Sun, C.-J., Shao-Horn, Y., \& Dincă, M. (2017). Conductive MOF electrodes for stable supercapacitors with high areal capacitance. Nature materials, 16(2), 220-224.

Simon, P., \& Gogotsi, Y. (2010). Materials for electrochemical capacitors. Nanoscience and technology: a collection of reviews from Nature journals, 320-329.

Song, X., Ma, X., Li, Y., Ding, L., \& Jiang, R. (2019). Tea waste derived microporous active carbon with enhanced doublelayer supercapacitor behaviors. Applied Surface Science, 487, 189-197.

Wang, H., \& Cui, Y. (2019). Nanodiamonds for energy. Carbon Energy, 1(1), 13-18.

Wang, Y., Zhang, L., Hou, H., Xu, W., Duan, G., He, S., . . . Jiang, S. (2021). Recent progress in carbon-based materials for supercapacitor electrodes: a review. Journal of Materials Science, 56(1), 173-200.

Xu, Y., Lin, Z., Zhong, X., Huang, X., Weiss, N. O., Huang, Y., \& Duan, X. (2014). Holey graphene frameworks for highly efficient capacitive energy storage. Nature communications, $5(1), 1-8$.

Yan, X., Yu, Y., \& Yang, X. (2014). Effects of electrolytes on the capacitive behavior of nitrogen/phosphorus co-doped nonporous carbon nanofibers: an insight into the role of phosphorus groups. RSC Advances, 4(48), 24986-24990.

Yumak, T. (2019). Electrochemical Performance of Fabricated Supercapacitors Using MnO2/Activated Carbon Electrodes. Hacettepe Journal of Biology and Chemistry, 47(1), 115122.

Zhang, L. L., \& Zhao, X. (2009). Carbon-based materials as supercapacitor electrodes. Chemical Society Reviews, 38(9), 2520-2531.

Zhang, W., Lin, N., Liu, D., Xu, J., Sha, J., Yin, J., . . . Lin, H. (2017). Direct carbonization of rice husk to prepare porous carbon for supercapacitor applications. Energy, 128, 618625.

Zhang, Y., Liu, S., Zheng, X., Wang, X., Xu, Y., Tang, H., . . . Luo, J. (2017). Biomass organs control the porosity of their pyrolyzed carbon. Advanced functional materials, 27(3), 1604687.

Zhu, X., Yu, S., Xu, K., Zhang, Y., Zhang, L., Lou, G., . . Shen, Z. (2018). Sustainable activated carbons from dead ginkgo leaves for supercapacitor electrode active materials. Chemical Engineering Science, 181, 36-45.

Zhu, Y., Murali, S., Stoller, M. D., Ganesh, K., Cai, W., Ferreira, P. J., . . . Thommes, M. (2011). Carbon-based supercapacitors produced by activation of graphene. science, 332(6037), 1537-1541. 